\title{
Impact of Climate Change on Fish Population Dynamics in the Baltic Sea: A Dynamical Downscaling Investigation
}

\author{
Brian R. MacKenzie, H. E. Markus Meier, Martin Lindegren, \\ Stefan Neuenfeldt, Margit Eero, Thorsten Blenckner, \\ Maciej T. Tomczak, Susa Niiranen
}

\begin{abstract}
Understanding how climate change, exploitation and eutrophication will affect populations and ecosystems of the Baltic Sea can be facilitated with models which realistically combine these forcings into common frameworks. Here, we evaluate sensitivity of fish recruitment and population dynamics to past and future environmental forcings provided by three ocean-biogeochemical models of the Baltic Sea. Modeled temperature explained nearly as much variability in reproductive success of sprat (Sprattus sprattus; Clupeidae) as measured temperatures during 1973-2005, and both the spawner biomass and the temperature have influenced recruitment for at least 50 years. The three Baltic Sea models estimate relatively similar developments (increases) in biomass and fishery yield during twenty-first century climate change (ca. $28 \%$ range among models). However, this uncertainty is exceeded by the one associated with the fish population model, and by the source of global climate data used by regional models. Knowledge of processes and biases could reduce these uncertainties.
\end{abstract}

Keywords Atmosphere-ocean models · Baltic Sea . Climate change $\cdot$ Temperature $\cdot$ Sprat $\cdot$ Downscaling

\section{INTRODUCTION}

The Baltic Sea and its biota have been and will continue to be impacted by various forcings including climate change, exploitation, and eutrophication (BACC Author Team 2008). One of the most likely climate-related changes that

Electronic supplementary material The online version of this article (doi:10.1007/s13280-012-0325-y) contains supplementary material, which is available to authorized users. will occur in this system, as well as globally, is a rise in temperature (Meier et al. 2011). Recent regionalized coupled climate-ocean models for the Baltic Sea suggest that temperatures will rise ca. $2-5{ }^{\circ} \mathrm{C}$, depending on model parameterisations, assumptions, emission scenarios, and season of the year (BACC Author Team 2008; Meier et al. 2011). Such a rise in temperature will have major impacts on biological processes, including direct effects on organism physiology and consequently habitat preferences, and indirectly via interactions through the food web (e.g., changes in phenologies and spatial-temporal overlap of predators and prey).

Currently, there are several climate-ocean models available for the Baltic Sea region and it is unknown which might perform best for fish population modeling purposes, or how sensitive population dynamics are to outputs from the different models. In this investigation, we use the Baltic sprat as a case study species to investigate these and related methodological issues regarding the incorporation of environmental information in fish population models. This species is useful for this purpose because of some existing knowledge of links between temperature and sprat ecology and because population models exist which directly incorporate temperature as a forcing variable (MacKenzie and Köster 2004; Lindegren et al. 2010; Ojaveer and Kalejs 2010; Casini et al. 2011). An initial objective of our study therefore is to investigate how well modeled temperatures as derived from state-of-the-art Baltic Sea models (Eilola et al. 2011; Meier et al. 2011) can reproduce past recruitment dynamics in this population.

A second and related objective will be to investigate how the combined influences of temperature and parental biomass (also referred to elsewhere in this report as spawning stock biomass or spawner biomass) affect recruitment. Several earlier studies using datasets covering 
shorter time periods have shown that spawner biomass has weak or no influence on recruitment in this stock for the given ranges of spawner biomass that were available (MacKenzie and Köster 2004; Baumann et al. 2006; Margonski et al. 2011). However, as population data are extended annually and frequently updated using newer, improved methodologies (ICES 2011), if new historical reconstructions become available for earlier time periods (Eero 2012), or if ecological processes associated with climate indices change over time, it is possible that the influences of spawner biomass and climate variability on recruitment could also change over time (Myers 1998). In the case of Baltic sprat, these issues can be addressed because the new reconstruction of spawner biomass and recruitment provides, respectively, 15 and 20 extra years of data for model testing, validation, and development. New models which directly include both the spawner biomass and the environmental forcing would be useful for fishery management decision making because effects of various fishing regulations (e.g., exploitation rates) could be simulated in a more explicit process-based approach.

The third objective of our study is to estimate the sensitivity of projected sprat biomass during the twenty-first century to oceanographic forcing provided by three different climate-ocean models of the Baltic Sea for a common greenhouse gas emission scenario (A1B) (Meier et al. 2012). We use these projections to compare the overall trends in sprat biomass and to explore the relative uncertainties associated with the different climate-ocean models relative to each other and associated with the fish population model itself.

\section{MATERIALS AND METHODS}

\section{Description of Atmosphere-Ocean Models}

Our main analysis uses outputs derived from the coupling of three oceanographic models of the Baltic Sea to two regional atmosphere model simulations. The oceanographic models have been described earlier (e.g. Eilola et al. 2011), and include two 3D circulation models with high horizontal resolution (ERGOM and RCO-SCOBI) and another modeling framework (BALTSEM) based on a spatial representation of the Baltic Sea in 13 sub-basins (see Meier et al. 2012 and references therein). One notable feature of the outputs from all three models is that they produce full time series of projected variables (known as "transient" simulations). The two main forcing datasets used in the study were results from a regional atmosphere model (Samuelsson et al. 2011), driven with ERA40 re-analysis data (Uppala et al. 2005) at the lateral boundaries, or with the results from a coupled atmosphere-ocean model (Döscher et al. 2002), driven with ECHAM5/MPIOM (Roeckner et al. 2006) global climate data, assuming the A1B emission scenario (Smith et al. 2000). The ERA40-forced model outputs from BALTSEM, ERGOM, and RCO-SCOBI were used primarily for investigation of hindcasted sprat recruitment, whereas the ECHAM5-forced model outputs have been used to produce scenario outputs for future climate.

A third forcing data set was used in one additional simulation of future climate for exploratory purposes. This forcing was provided by the Hadley Centre global climate model (GCM) HadCM3 (Gordon et al. 2000). The forcing from this global model, also under the A1B emission scenario, was used with the RCO-SCOBI regional climateocean model to produce another set of temperature data. This forcing allowed us to compare the sensitivity of projected temperature and fish biomass to different global forcing datasets for a common regional climate-ocean model and emission scenario.

\section{Development of Temperature Datasets from Field Observations}

We used data collected at sea and archived in the Hydrographic Database of the International Council for the Exploration of the Sea (ICES) for analyses of sprat recruitment. A description of the field-derived datasets is available in the Electronic supplementary information.

\section{Evaluation of Coupled Atmosphere-Ocean Models for Modeling Sprat Recruitment}

Sprat recruitment data from a recent international assessment (ICES 2011) are available for the year classes 1973-2009 for ICES subdivisions 22-32, which is the area including the Belt Sea, Øresund, western Baltic Sea, Baltic proper, and northern Gulfs.

We used observed temperature data from ICES and the ERA40-forced model outputs (described below) for parameterising sprat spawner biomass-environment-recruitment models for different time periods. Given the available time series of hindcasted ERA40 data from all three models (1970-2005), we initially restricted our recruitment analyses to the year classes 1973-2005. We used May or August temperatures from, respectively, the Bornholm Basin and Baltic Proper (see Electronic supplementary material for location and depth details) as predictor of sprat recruitment data. Prior to these analyses, recruitment data were ln-transformed to stabilize variance. Effects of temperature on $\ln$ recruitment were quantified using ordinary least squares linear regression. Analyses were conducted using the observed temperature data, and the hindcasted 
ERA40 data from each of the three oceanographic models (BALTSEM, ERGOM, RCO-SCOBI).

We investigated the combined roles of spawner biomass and temperature on recruitment variability in subsequent analyses. We evaluated whether standard models of stockrecruitment dynamics (i.e., Ricker, Beverton-Holt) and including temperature data could explain significant variability in past recruitment. Analyses involving modeled temperature only used August temperatures, as these have been shown to explain more variability in recruitment than spring temperatures (Baumann et al. 2006; see also results below). Our main objective with this set of analyses was to develop a parsimonious function linking spawner biomass and temperature to recruitment which could be used in future climate change scenarios, rather than to identify factors which explain maximal variability in sprat recruitment. The recruitment models were fit using nonlinear regression for the longest time period for which datasets were available (1960-2009; see below) and for the shorter period for which modeled temperatures were available (1974-2005).

Most of our recruitment modeling analyses used recruitment estimated at age 1 as derived from singlespecies stock assessments (ICES 2011). However, recruitment at age 0 is available from multi-species stock assessments which directly incorporate the effects of cod predation on sprat, as well as other species interactions among sprat, cod, and herring (Köster et al. 2009). We conducted a limited number of analyses using 0-group data from an updated version of this model to illustrate the applicability of our results and methods to this age group. Analyses included effects on recruitment of modeled August temperature from one of the climate-ocean models (RCO-SCOBI) and observed temperature, and parameterisation of the Ricker spawner biomass-recruitment model, using observed and modeled (RCO-SCOBI) August temperature.

\section{Validation and Development of Temperature- Dependent Spawner Biomass-Recruitment Models Using Independent Data (1955-2009)}

A new extended time series of spawner biomass and recruitment data (Eero 2012) was used to evaluate whether the influence of temperature observed post-1973 was also evident and consistent with independent data from a different time period. We used the relationships between recruitment and temperature (May, August) for 1974-2009 to predict the recruitment for year classes 1955-1973. We then compared recruitment with temperature using the entire time period available (1955-2009). We also investigated whether Ricker spawner biomass-environmentrecruitment models could be fit to the entire time series from 1960 to 2009. This analysis used August temperature only.

\section{Projections of Sprat Biomass During the Twenty- First Century Using Combined Climate- Oceanographic-Fish Population Models}

We integrated the regionalized climate-ocean model outputs of temperature with a standard age-structured model of fish population dynamics to make scenario projections of the development of the Baltic sprat stock during the twenty-first century. The modeled temperatures were derived from each of the three oceanographic models coupled to the ECHAM5 modeled climate dataset and for the RCO-SCOBI model coupled to the HadCM3 modeled climate dataset for the A1B greenhouse gas emission scenario. The main features of the fish population projection model as configured for sprat and other species have been described earlier (MacKenzie et al. 2011), and a short summary is presented in Electronic supplementary material. The model employs a new temperature-dependent spawner biomass-recruitment model based on year classes 1960-2009 (described below). Simulations evaluated two levels of fishing mortality (status quo and sustainable level, $F_{\text {msy }}$ ), and the sensitivity of population development to the assumed magnitude of natural mortality imposed by predators (e.g., cod).

\section{RESULTS}

\section{Temperature Effects on Observed Sprat Recruitment}

Both the observed and the modeled temperatures from all three oceanographic models forced with ERA40 data explained highly significant levels of variability in sprat recruitment. When May temperatures were used, observed data explained $21 \%$ of the variance, whereas modeled temperature from two of the three models was associated with nearly as much (18\%) variability (Fig. S1; Table S1 in Electronic supplementary material).

August temperatures were associated with higher levels of recruitment variability than May temperatures (Fig. S1; Table S1 in Electronic supplementary material). Observed temperatures were associated with higher levels of recruitment variability $\left(R_{\mathrm{adj} .}^{2}=0.58 ; P<0.0001\right)$ than modeled temperatures, although nearly all observed and modeled temperature datasets explained highly significant $(P<0.01)$ levels of variability. Modeled temperature from the RCO-SCOBI hydrographic model was more highly correlated with recruitment than temperatures calculated using the other two models. 
These effects of temperature also were evident when validated with independent historical data. Models using observed temperature data and based on the year-classes 1974-2009 explained significant levels of variability in recruitment during the years 1955-1973 (Fig. 1; Table S1 in Electronic supplementary material). August temperature was more effective than May because its correlation was significant and slope and intercept of the observed versus predicted relationship were not significantly different from 1 and 0, respectively. Relationships using the entire time period 1955-2009 were highly significant for both the May and the August temperatures (Fig. 1; Table S1 in Electronic supplementary material). Temperature (observed and modeled) also explained significant levels of variability in 0-group sprat recruitment (Table S1 in Electronic supplementary material). Levels of explained variability in age 0 recruitment were approximately similar to or higher than those obtained using age 1 recruits.

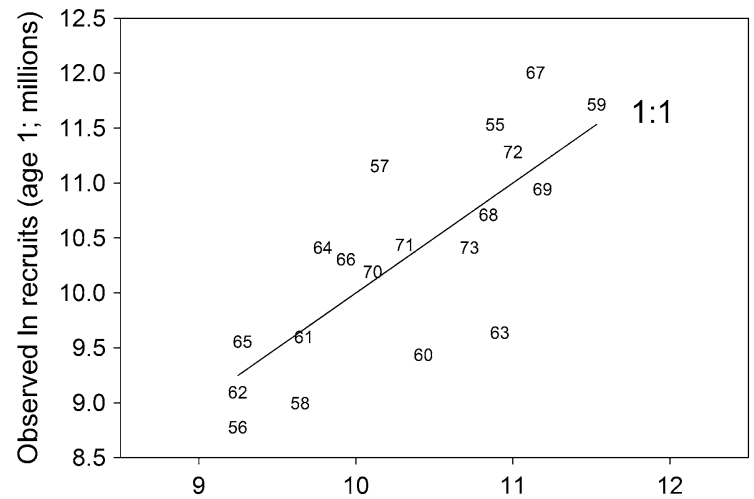

Ln recruits (age 1) predicted from August temperature (millions)

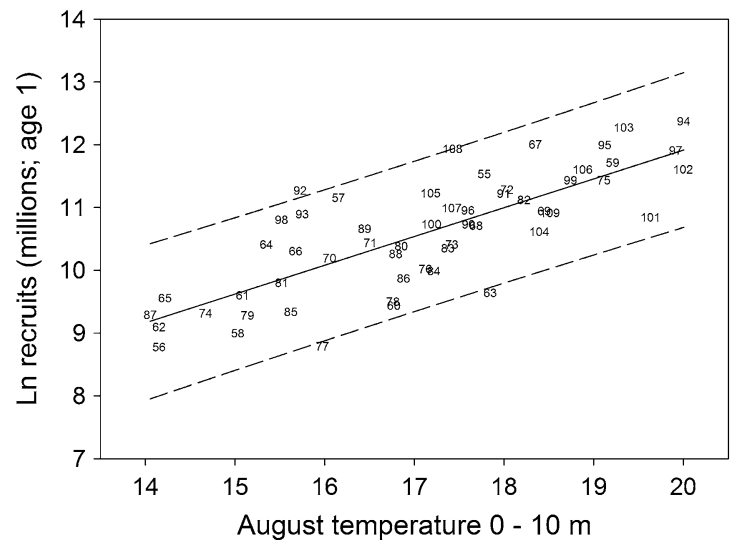

Fig. 1 Top panel Validation of recruitment-temperature relationship constructed for Baltic sprat year classes 1974-2009 with independent data for year classes 1955-1973). Bottom panel Relationship between In recruitment (millions) and August temperature for year classes 1955-2009. The regression line is $\ln$ Recruits $=0.459 * T+2.744$ $\left(R_{\text {adj. }}^{2}=0.61 ; P<0.0001 ; \mathrm{SE}_{\mathrm{est}}=0.592 ; N=55\right)$. Symbols are year classes and dashed lines in bottom panel show $95 \%$ prediction limits

\section{Combined Influences of August Temperature and Spawner Biomass on Observed Sprat Recruitment}

Spawner biomass-recruitment models (i.e., Ricker, Beverton-Holt) excluding temperature generally could not explain past variations in recruitment (Electronic supplementary material, Table S2 in Electronic supplementary material); models either could not be parameterized or were not statistically significant. Inclusion of observed temperature in both the models resulted in statistically significant fits, although the spawner biomass term was only significant in the Ricker model (Table S2 in Electronic supplementary material). Including both the spawner biomass and the temperature in the Ricker model enabled $44 \%$ of the variability in recruitment to be explained for year classes 1974-2009 or 52\% for the period 1960-2009 (Fig. 2). Moreover, the average residual error of the fitted model for 1960-2009 was lower than that for shorter periods $\left(\mathrm{SD}_{\mathrm{est}}=3688\right.$ vs. $>43000$; Table $\mathrm{S} 2$ in Electronic supplementary material). This model with its longer time period and modest explanatory power was therefore selected for population simulation modeling.

Modeled August temperatures also explained significant levels of recruitment variability, although spawner biomass-recruitment models including modeled temperatures explained less variability than models using observed temperatures (Table S2 in Electronic supplementary material). Ricker models using 0-group recruitment with observed and modeled temperature were also significant. Ricker models using 0- or 1-groups explained similar levels of recruitment (Table S2 in Electronic supplementary material).

\section{Projected Temperatures}

The ECHAM5- and HadCM3-forced model climatologies of temperature distributions overlap with those of observed data for the period 1970-2005 during both May and August. However, the models performed differently depending on month and forcing (Fig. 3). The most notable difference is seen with HadCM3 forcing of the RCO-SCOBI model. During May, this climatology was lowest during both the hindcast and the projection periods; in contrast, during August, HadCM3_RCO-SCOBI produced highest outputs during historical and future time periods (Fig. 3).

The three oceanographic models forced with ECHAM5 climate data yielded similar estimates of projected mean May temperature in the final three decades of the twentyfirst century. Temperatures from the three models are expected to be ca. $3{ }^{\circ} \mathrm{C}$ higher than the climatological mean for 1955-2009 based on observations, i.e., ca. 6 versus $3{ }^{\circ} \mathrm{C}$ (Fig. 3). For August, the three models differed somewhat in 
Fig. 2 Estimated relationship between spawner biomass and recruitment for sprat in the Baltic Sea for year classes 1960-2009. The model is $R=0.178 \mathrm{Se}^{-0.0011 \mathrm{~S}+0.396 \mathrm{~T}}$ $\left(R_{\text {adj. }}^{2}=0.52 ; P=0.0002\right.$ and $<0.0001$ for the spawner biomass and temperature coefficients, respectively; $\mathrm{SE}_{\text {est }}=36822 ; N=50$ ). The black solid line is the fit of the model for the average temperature during the time period; red and blue lines show fits for temperatures $1 \mathrm{SD}$ higher and lower than the mean temperature. Sprat data source: (Eero 2012)

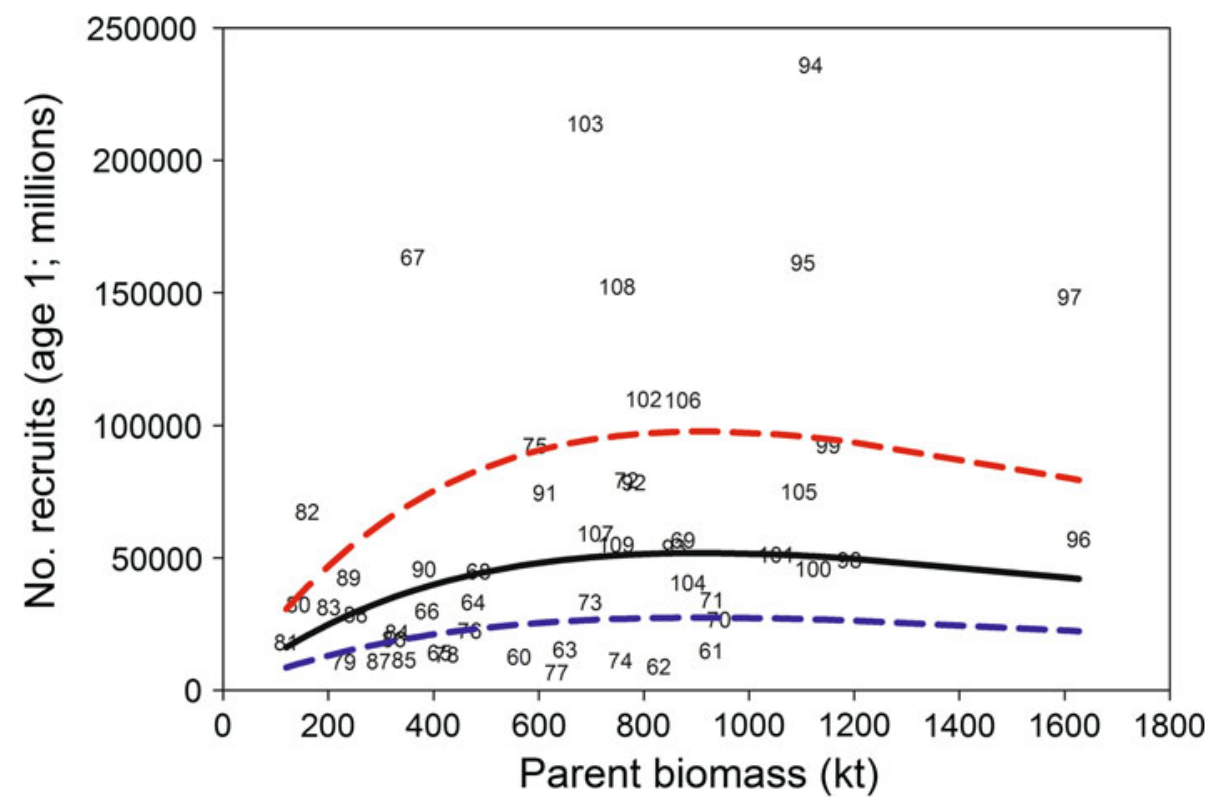

their projected mean temperatures for 2070-2100 (range = 18.6-19.6; Fig. 3). One of the models (ERGOM) projects a higher temperature than the other two models (Fig. 3). The increase in temperature across the three models is expected to be ca. $1.6-2{ }^{\circ} \mathrm{C}$ and therefore approximately 30-50\% less than the increase in May temperature. ERGOM model temperatures rise more than BALTSEM and RCO-SCOBI temperatures in August but all three models show similar rises in May. Variability of the projected temperatures for all models and both the months is less than the variability observed in the historical period; in May modeled variance was ca. $50 \%$ less than observed climatological variance, and in August, some model variances were even lower (Fig. 3).

The rise in May temperature throughout the century is approximately linear, although some models suggest an initial 1-2 decades with weak or no increase in temperature, followed by an approximate linear upward trend (BALTSEM, ERGOM; Fig. 3). In comparison, projected August temperatures tend to rise sharpest during ca. 2020-2065. Temperatures in the first 10-15 years decline before increasing in the 2020s. Temperatures in the last ca. 3 decades of the twenty-first century appear to stabilize and fluctuate around model-specific means. The Hadley model forcing of the RCO-SCOBI model produced August temperatures which were much higher than those seen using ECHAM5 forcing for any of the three regional climateocean models (Fig. 3). Temperatures averaged $21.5^{\circ} \mathrm{C}$ during the last three decades of the twenty-first century $\left(>4{ }^{\circ} \mathrm{C}\right.$ warmer than the observed climatology for 1955-2010), and were frequently outside the $95 \%$ confidence limits of the ECHAM5-forced RCO-SCOBI simulation. This temperature projection continued to rise throughout the century.

\section{Projections of Sprat Spawner Biomass and Fishery Yields in the Baltic Sea for the Twenty-First Century}

Sprat spawner biomass is expected to increase during the twenty-first century, based on outputs from all three models subjected to ECHAM5 or from RCO-SCOBI model using HadCM3 forcing. Considering first the ECHAM5 forcing, final mean biomass (e.g., during 2070-2100), assuming sustainable exploitation levels $\left(F_{\mathrm{msy}}=0.32\right)$ and current levels of natural mortality, is estimated to be ca. 1.4-1.8 million tonnes and therefore similar to the maximum observed in the past (Fig. 4). Such a biomass could support annual fishery yields of ca. 340-420 kt (Fig. S2 in Electronic supplementary material).

Projected sprat biomass is sensitive to assumed levels of natural mortality (Fig. S3 in Electronic supplementary material). If natural mortality was $50 \%$ lower than status quo levels, mean biomass would increase to nearly 2 million tonnes by end of the twenty-first century, based on the RCOSCOBI temperature forcing. In contrast, higher natural mortality (i.e., 2.2-fold higher than status quo) corresponding to the maximum observed during 1974-2010 would cause the biomass to fall to ca. 150000 tonnes in the 2020s before increasing again to ca. 1 million tonnes by end of the twentyfirst century (Fig. S3 in Electronic supplementary material).

Comparison of the different ECHAM5-forced model projections with their $95 \%$ confidence intervals shows that the range of model median spawner biomass of all three 

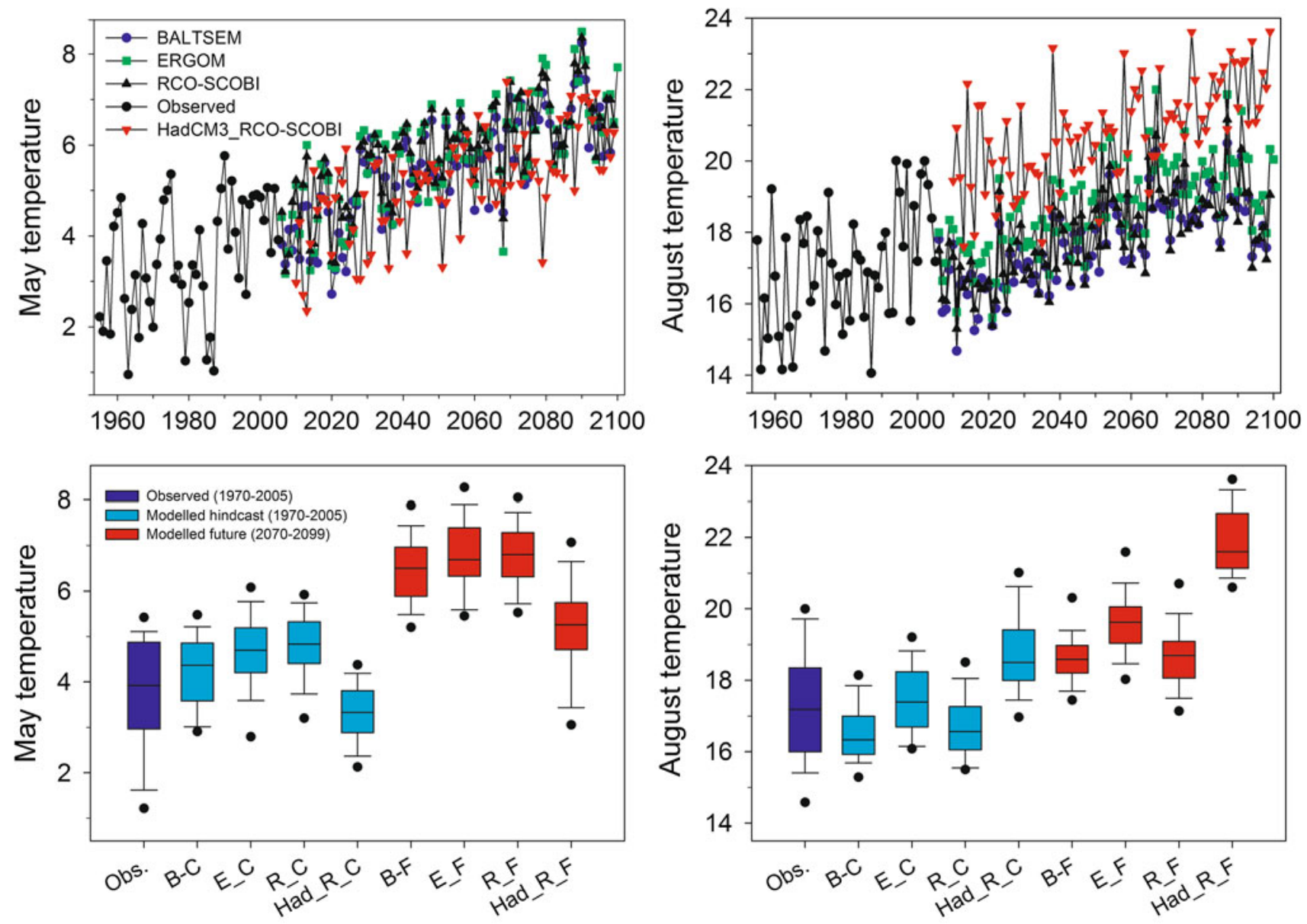

\section{Data source}

Fig. 3 Top panels Projected temperatures for May and August using three climate-ocean models (BALTSEM, ERGOM, RCO-SCOBI) forced with ECHAM5 boundary data and one climate-ocean model (RCO-SCOBI) forced with HadCM3 boundary data. Also shown are observed temperatures during 1955-2010. Modeled temperatures available for the historic period are not shown for clarity. May temperatures are depth averaged between 45 and $65 \mathrm{~m}$ (observations) or 40 and $60 \mathrm{~m}$ (modeled data) in the Bornholm Basin. August temperatures are depth averaged in the layer $0-10 \mathrm{~m}$ in the Baltic

models lies well within the $95 \%$ confidence interval of any single model (Fig. 4). Here, we show only the $95 \%$ confidence intervals for the ECHAM5-RCO-SCOBI projection because temperatures from this model (forced with ERA40 data) explained highest levels of sprat recruitment variability in the historical period 1973-2005 (Electronic supplementary material. Table S1 in Electronic supplementary material). However, this range spans the range of median spawner biomasses simulated by all three coupled ocean-population models for nearly all years in the forecast period, so employing confidence intervals from other models would give similar results. Variability of estimated median biomass when estimated using output from the three different climate-oceanographic-fish population

models is therefore less than the variability (i.e., $95 \%$ confidence limits) of estimated biomass within any of these models which, as configured here, is entirely associated with the uncertainty of the stock-environment-recruitment relationship. The range of median spawner biomasses when these are estimated using temperatures simulated by the three biogeochemical models is ca. $28 \%$ on average (minimum-maximum $=2-66 \%$; Fig. 4). Similar levels of between-model uncertainty are evident for fishery yields (Fig. S3 in Electronic supplementary material).

As expected from its higher projected temperature, the HadCM3-forced RCO-SCOBI projections of sprat biomass and yield are much higher (ca. twofold) than those projected by ECHAM5 forced models. 

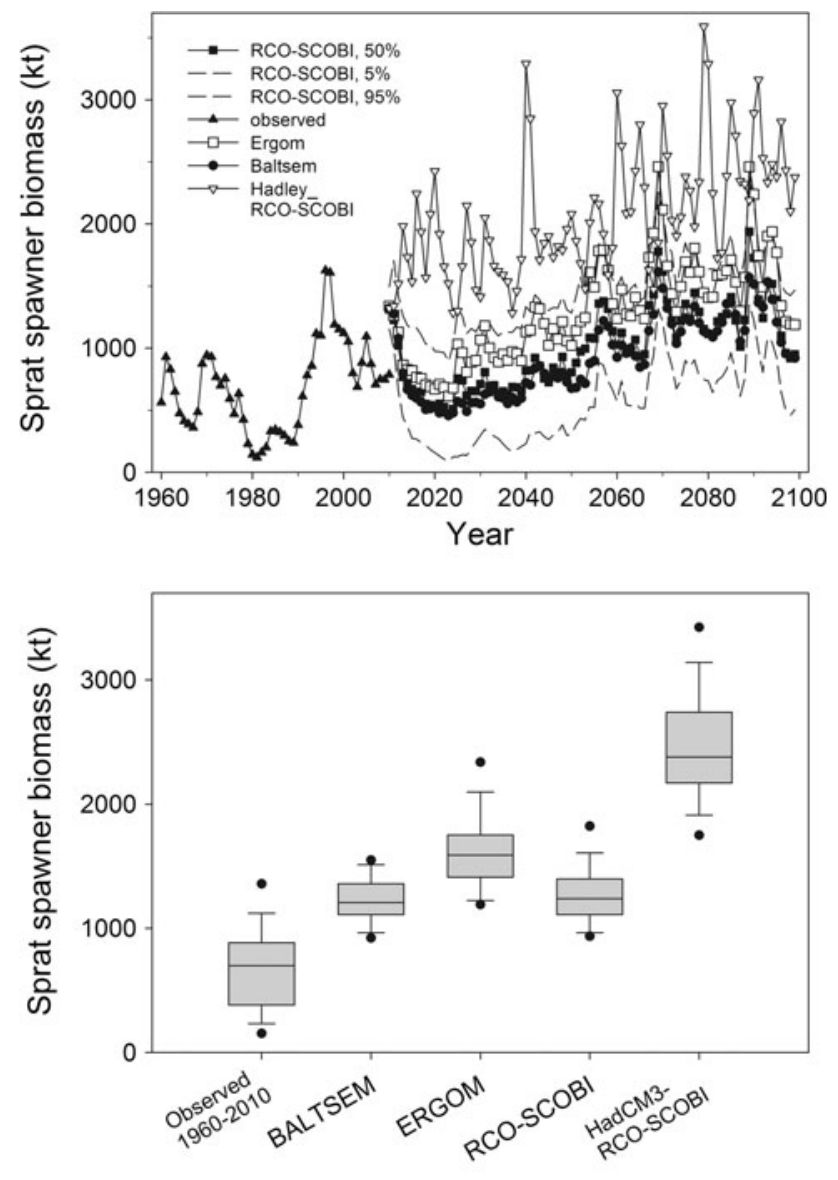

Data source

Fig. 4 Projected spawner biomass of sprat in the Baltic Sea (ICES Subdivisions 22-32) assuming a temperature-driven spawner-recruit relationship with temperatures estimated from three different climateoceanographic models forced with ECHAM5 modeled climate data and one model (RCO-SCOBI) forced with HadCM3 modeled climate data according to the A1B greenhouse gas emission scenario. Dashed black lines The $95 \%$ confidence limits of spawner biomass as estimated by the fish population model forced by temperature output from RCO-SCOBI (the climate-ocean model with least uncertainty in explaining sprat recruitment variability during 1974-2005). Fishing mortality of sprat was at a currently defined sustainability level $(F=0.32$; ICES 2011) and natural mortality (e.g., due to predation by cod and seals) was assumed equal to the mean level during 2008-2010. Also shown (triangles) are historical estimates of spawner biomass during 1960-2010 (ICES 2011; Eero 2012). Additional details of calculations are in the text. Bottom panel Summary boxplot statistics (see Fig. 3 for description) for observed historical period 1960-2010 and simulated data for years 2070-2099

\section{DISCUSSION}

\section{Sprat Recruitment Dynamics and Temperature}

Using a newly constructed analytical time series of sprat recruitment, we have shown that temperature has been associated with sprat recruitment variations during 55 years. This correlation is one of the longest quantified recruitment-environmental relationships in the fisheries ecological literature. As such, it demonstrates the important role of climate variability on this population, and via the ecological role of this species in the food web, indirectly on food web structure and function. The influence of temperature on sprat recruitment was evident in a test of a model with separate independent data. This test showed that August temperature could explain significant variations in recruitment outside the time period of model construction, and as demonstrated earlier (Baumann et al. 2006), it explained higher levels of variability in recruitment than spring temperatures. The finding that August and May temperature correlate strongly with recruitment over such long time periods is surprising, given the common pattern of model breakdown as time progresses (e.g., Myers 1998). The Baltic Sea has progressed through at least two regimes and has been influenced by at least one additional major human perturbation (eutrophication) during the time period of this analysis (Casini et al. 2009; Möllmann et al. 2009; Eero et al. 2011). Despite major changes in productivity and food web structure, the robustness of the response to temperature illustrates that temperature has an important influence on sprat ecology in the Baltic Sea (Ojaveer and Kalejs 2010).

Our analyses have shown that temperature outputs from the three climate-ocean models can quantify past variations in the recruitment dynamics of a key species in the Baltic food web. Modeled temperature alone explained nearly half the variability in recruitment during 1973-2005. The new results, showing that recruitment depends on both the temperature and the spawner biomass and over different time periods up to 50 years, facilitate projections of how the stock could be influenced by combined impacts of climate change, exploitation, and eutrophication. As exploitation influences parental biomass, this impact can be directly included in new population projection models. The shape of the fitted Ricker models for mean, mean +1 standard deviation and mean -1 standard deviation temperature are relatively flat above spawner biomasses ca. $800 \mathrm{kt}$. The flatness of the curves suggests a wide range of spawner biomass over which recruitment may vary independently of spawner biomass. The flatness indicates that density-dependent processes such as egg cannibalism (Köster and Möllmann 2000) are not strong enough to cause declines in recruitment substantially below maximum recruitment.

\section{Projections of Sprat Biomass and Yield in the Twenty-First Century}

The simulations of future population development presented here should be considered as "works-in-progress" and are not yet definitive because they contain many 
simplifications, biases, and assumptions. In particular, our projected biomasses are not directly comparable with historic ones because of bias in modeled temperature relative to historical climatologies (Fig. 3). Our main focus in this investigation has been the sensitivity of future biomass to the different climate-oceanographic model formulations and forcings, rather than estimation of absolute expected changes in biomass relative to historical levels. Some of the uncertainty associated with future biomass projections is given by the source of the boundary forcing from GCMs (i.e., ECHAM5 or HadCM3). Substantial differences in projected temperature, and subsequently sprat biomass (see below) are evident when these two forcings are applied to a common regional climate-ocean model (RCO-SCOBI).

Within model runs using identical forcing conditions, uncertainty associated with different regionalized climateocean models was quantified. The variability (based on $95 \%$ confidence limits) of spawner biomass projections produced using a given climate-ocean model (e.g., RCO$\mathrm{SCOBI}$ ) as forcing to the fish population model is larger than the range in median spawner biomass from the three different climate-ocean models (forced using ECHAM5). This comparison suggests that the current regionalized climate-ocean models, at least with respect to summer surface temperatures, collectively have less uncertainty than the fish population model. The fish population model itself only includes uncertainty in one, arguably the most important, biological process (the stock-recruitment relationship); although this process often dominates fish population dynamics and productivity variations (Hilborn and Walters 1992), inclusion of natural variations in other fish biological parameters (e.g., growth, maturation, and mortality rates) could increase the uncertainty beyond what is presently represented by our analyses. Given that the spawner-recruit relationship is uncertain and that it has such importance in fish population dynamics, new studies of factors affecting recruitment could potentially lead to relationships with higher explanatory power and more precise projections.

As noted above, there are some differences in projected temperatures between the three oceanographic models. This finding is perhaps expected because the three climateocean models have different parameterisations; more generally, it is typical that models differ in their performance relative to each other and to observed data (Hare et al. 2010; Eilola et al. 2011; Stock et al. 2011; Broberg and Christensen 2012). The modeling approach employed here, in which raw climate-ocean outputs were used in subsequent population analyses without bias adjustment relative to observed oceanographic data, transfers the betweenmodel temperature variability directly through to the fish responses. As a result, the sensitivity of mean biomass to the climate-ocean models is transparent and can be quantified. During the last 3 decades of the simulation period, the range in median biomass was ca. $28 \%$ among the three models and sometimes reached $66 \%$. The potential range of projected biomass or fishery yield across models can perhaps be reduced in future via application of bias adjustments (Broberg and Christensen 2012).

The combined ECHAM5 climate-ocean-fish population models suggest that median sprat spawner biomass could increase during the twenty-first century to levels of ca. 1.5 million tonnes under presently defined levels of sustainable exploitation (i.e., $F_{\mathrm{msy}}=0.32$; ICES 2011) and status quo estimates of natural mortality. This level with its $95 \%$ confidence limits is comparable to some other projections of sprat spawner biomass in the Baltic Sea using different fish and food web model parameterisations and environmental forcings (ICES 2010; Lindegren et al. 2010). Higher biomasses and yields are projected using the HadCM3 forcing. We caution, however, that these latter estimates are particularly uncertain because the projected increase in sea temperature using HadCM3 forcing leads to temperatures which in most years exceed the range on which our Ricker spawner biomass-recruitment-temperature relationship has been parameterised. For example, such warm temperatures may cause a shift in spawning time to cooler times of year (Karasiova 2002) as is seen in the Black Sea (Satilmis et al. 2003). In such cases, projected recruitment would be lower than that projected using simulated August temperatures. These HadCM3 projections of biomass are therefore less reliable than those based on ECHAM5 forcing.

Due to the nonlinear increase in projected sea temperature seen in ECHAM5 projections, the increase in sprat biomass is also nonlinear. Most of the biomass increase is projected to occur in the mid-late decades when projected temperatures increase sharpest, and following 1-2 decades of slightly declining or stable biomass relative to the early 2000s. The initial decline or stable level of biomass in the 2010s-early 2020s is due mainly to a stable or even slightly declining temperature in the first decade of the scenario simulation. The decline in sprat biomass could be reinforced by the currently increasing biomass of cod (ICES 2011).

The forecasted mean sprat biomass using ECHAM5 forcing in the final two decades of the twenty-first century is approximately similar to the historically observed maximal biomass (Fig. 4). Consequently, it is reasonable to ask what the carrying capacity of the Baltic Sea for sprat is and whether such high projected biomasses could occur and be sustained in future. Some insight to this question can potentially be derived from sprat dynamics and spatial distributions within the Baltic Sea during the past 10-20 years. Sprat biomass is now predominantly (ca. $80 \%$ ) distributed in the northern Baltic proper, where its 
abundance has historically been much lower (Casini et al. 2011). The reasons for the increase in the spatial distribution in the north are reduced predation by cod in these areas, coupled with a more favorable (warmer) thermal environment in recent decades (Casini et al. 2011). However, much of its former habitat area in the southern Baltic proper (e.g., subdivisions 25-26) is now vacated, probably due to increased abundance of and predation by cod. Should future climate change lead to a reduction in cod biomass (Lindegren et al. 2010; MacKenzie et al. 2011), then these southern areas of the Baltic proper could potentially become re-populated by sprat. In addition, increases of sprat abundance in the large gulfs of the northern Baltic Sea (e.g., Gulf of Finland, Gulf of Bothnia) might also occur if temperatures and salinity remain suitable for sprat reproduction. These considerations suggest that there is potential for an increase in sprat spawner biomass to and potentially beyond the maximal level seen in the early-mid 1990s. Such an increase assumes that overall energy flows and trophic relationships (e.g., levels of primary production required to support the expected increase in fish production) can remain in balance (Tomczak et al. 2012).

Our simulations include a sensitivity analysis of one of the main species interactions which affects sprat biomass (i.e., predation). This analysis showed, expectedly, that higher natural mortality results in lower projected sprat biomasses and fishery yields, but would not be sufficient to prevent the sprat biomass from increasing under the assumed exploitation levels. This observation suggests that climate change will have a dominant effect on sprat dynamics relative to the roles of predators on ages $1+$, under the assumed fishing levels used here. For example, the relatively stable or even declining temperatures in the 2010s and 2020s, when combined with increasing natural mortality, could lead to a reduction in sprat biomass below historically observed levels during 1974-2010 to ca. 180000 tonnes. Such low levels would lead to low fishery yields and likely impact predator and prey biology (e.g., growth, reproduction) in the food web (Casini et al. 2009, 2011).

The spawner-recruit relationship which we have used explains $>50 \%$ of past variability. However, previous attempts to quantify past variability in recruitment have not been able to detect an influence of spawner biomass, so the current relationship, although uncertain, facilitates direct incorporation of fishing effects on the population in a realistic way: fishing via removal of adults and juveniles reduces the population biomass of reproductive individuals, thereby potentially leading to a reduction in offspring production. We note, however, that the parameters of this relationship could change as new data become available or if the methodology for assessment changes substantially in future years; continued monitoring and updating of the relationship is recommended in the future.

\section{CONCLUSIONS}

Sea temperature and spawner biomass have significantly influenced recruitment of sprat in the Baltic Sea since 1960. These effects have been incorporated into a combined climate-ocean-biogeochemical-population modeling framework to simulate how sprat biomass could be influenced by expected climate change and exploitation during twenty-first century. All model-forcing combinations project an increase in biomass and expected fishery yields under sustainable exploitation. Major sources of uncertainty, given a greenhouse gas emission scenario, are the GCM forcings and the spawner biomass-recruitment relationship. In comparison, given a set of climatic conditions, projected temperatures from the three regional climateocean models are quite similar.

Acknowledgments DTU Aqua has received funding from the European Community's Seventh Framework Programme (FP/ 2007-2013) under grant agreement nu 217246 made with the joint Baltic Sea research and development programme BONUS, and from the Danish National Science Foundation (ECOSUPPORT project). We thank the Danish National Research Foundation (Dansk Grundforskningsfond) for support to the Center for Macroecology, Evolution and Climate, University of Copenhagen and DTU Aqua. We thank ECOSUPPORT colleagues (Kari Eilola, Bo Gustafsson, Ivan Kuznetsov, Bärbel Müller-Karulis, Thomas Neumann) for assistance with computations, extractions, and compilations of model data. We thank Anders Nielsen and Andy Visser for statistical assistance, Else Juul Green of ICES for assistance with extraction of hydrographic data from the ICES Hydrographic Database, and the guest editor team for support, patience and assistance.

\section{REFERENCES}

BACC Author Team. 2008. Assessment of climate change for the Baltic Sea basin. Berlin: Springer.

Baumann, H., H.H. Hinrichsen, C. Möllmann, F.W. Koster, A.M. Malzahn, and A. Temming. 2006. Recruitment variability in Baltic Sea sprat (Sprattus sprattus) is tightly coupled to temperature and transport patterns affecting the larval and early juvenile stages. Canadian Journal of Fisheries and Aquatic Sciences 63: 2191-2201.

Broberg F., and J.H. Christensen. 2012. Overestimation of Mediterranean summer temperature projections due to model deficiencies. Nature Climate Change. doi:10.1038/nclimate1454.

Casini, M., J. Hjelm, J.C. Molinero, J. Lövgren, M. Cardinale, V. Bartolino, A. Belgrano, and G. Kornilovs. 2009. Trophic cascades promote threshold-like shifts in pelagic marine ecosystems. Proceedings of the National Academy of Sciences of the United States of America 106: 197-202.

Casini, M., G. Kornilovs, M. Cardinale, C. Moellmann, W. Grygiel, P. Jonsson, T. Raid, J. Flinkman, et al. 2011. Spatial and temporal density dependence regulates the condition of central 
Baltic Sea clupeids: Compelling evidence using an extensive international acoustic survey. Population Ecology 53: 511-523. doi:10.1007/s10144-011-0269-2.

Döscher, R., U. Willen, C. Jones, A. Rutgersson, H. Meier, U. Hansson, and L. Graham. 2002. The development of the regional coupled ocean-atmosphere model RCAO. Boreal Environment Research 7: 183-192.

Eero M. 2012. Reconstructing the dynamics of sprat (Sprattus sprattus) in the Baltic Sea in the 20th century. ICES Journal of Marine Science. doi:10.1093/icesjms/fss051.

Eero, M., B.R. MacKenzie, F.W. Köster, and H. Gislason. 2011. Multi-decadal responses of a cod (Gadus morhua) population to human-induced trophic changes, exploitation and climate variability. Ecological Applications 21: 214-226.

Eilola, K., B.G. Gustafsson, I. Kuznetsov, H.E.M. Meier, T. Neumann, and O.P. Savchuk. 2011. Evaluation of biogeochemical cycles in an ensemble of three state-of-the-art numerical models of the Baltic Sea. Journal of Marine Systems 88: 267-284. doi:10.1016/j.jmarsys.2011.05.004.

Gordon, C., C. Cooper, C.A. Senior, H. Banks, J.M. Gregory, T.C. Johns, J.F.B. Mitchell, and R.A. Wood. 2000. The simulation of SST, sea ice extent and ocean heat transports in a version of the Hadley Centre coupled model without flux adjustments. Climate Dynamics 16: 147-166.

Hare, J.A., M.A. Alexander, M.J. Fogarty, E.H. Williams, and J.D. Scott. 2010. Forecasting the dynamics of a coastal fishery species using a coupled climate-population model. Ecological Applications 20: 452-464. doi:10.1890/08-1863.1.

Hilborn, R., and C. Walters. 1992. Quantitative fisheries stock assessment: Choice, dynamics and uncertainty. New York: Chapman and Hall.

ICES. 2010. Report of the ICES/HELCOM working group on integrated assessments of the Baltic Sea (WGIAB). ICES CM 2010/SSGRSP:02, 1-98.

ICES. 2011. Report of the Baltic fisheries assessment working group. ICES CM 2011/ACOM: 10, 1-824.

Karasiova, E. 2002. Variability of sprat peak spawning and larvae appearance timing in the southeastern Baltic Sea during the past six decades. Bulletin of the Sea Fisheries Institute 2: $57-67$.

Köster, F., and C. Möllmann. 2000. Egg cannibalism in Baltic sprat Sprattus sprattus. Marine Ecology-Progress Series 196: 269-277. doi:10.3354/meps196269.

Köster, F.W., M. Vinther, B.R. MacKenzie, M. Eero, and M. Plikshs. 2009. Environmental effects on recruitment and implications for biological reference points of eastern Baltic cod (Gadus morhua). Journal of Northwest Atlantic Fishery Science 41: 205-220.

Lindegren, M., C. Möllmann, A. Nielsen, K. Brander, B.R. MacKenzie, and N.C. Stenseth. 2010. Ecological forecasting under climate change: The case of Baltic cod. Proceedings of the Royal Society London B 277: 2121-2130.

MacKenzie, B.R., and F.W. Köster. 2004. Fish production and climate: Sprat in the Baltic Sea. Ecology 85: 784-794.

MacKenzie B.R., M. Eero, and H. Ojaveer. 2011. Could seals prevent cod recovery in the Baltic Sea? Plos One 6: e18998-1-9. doi: 10.1371/journal.pone.0018998.

Margonski, P., S. Hansson, M.T. Tomczak, and R. Grzebielec. 2011. Climate influence on Baltic cod, sprat, and herring stockrecruitment relationships. Progress in Oceanography 87: $277-288$

Meier H.E.M., H.C. Andersson, K. Eilola, B.G. Gustafsson, I. Kuznetsov, B. Müller-Karulis, T. Neumann, and O.P. Savchuk. 2011. Hypoxia in future climates-a model ensemble study for the Baltic Sea. Geophysical Research Letters 38: 6. doi: http://dx.doi.org/10.1029/2011GL049929.
Meier H.E.M., B. Mueller-Karulis, H.C. Andersson, C. Dieterich, K. Eilola, B.G. Gustafsson, A. Hoeglund, R. Hordoir, et al. 2012. Impact of climate change on ecological quality indicators and biogeochemical fluxes in the Baltic Sea-a multi-model ensemble study. AMBIO. doi:10.1007/s13280-012-0320-3.

Möllmann, C., R. Diekmann, B. Muller-Karulis, G. Kornilovs, M. Plikshs, and P. Axe. 2009. Reorganization of a large marine ecosystem due to atmospheric and anthropogenic pressure: A discontinuous regime shift in the Central Baltic Sea. Global Change Biology 15: 1377-1393.

Myers, R.A. 1998. When do environment-recruitment correlations work? Review in Fish Biology and Fisheries 8: 285-305.

Ojaveer, E., and M. Kalejs. 2010. Ecology and long-term forecasting of sprat (Sprattus sprattus balticus) stock in the Baltic Sea: A review. Reviews in Fish Biology and Fisheries 20: 203-217. doi: 10.1007/s11160-009-9130-5.

Roeckner, E., R. Brokopf, M. Esch, M. Giorgetta, S. Hagemann, L. Kornblueh, E. Manzini, U. Schlese, et al. 2006. Sensitivity of simulated climate to horizontal and vertical resolution in the ECHAM5 atmosphere model. Journal of Climate 19: 3771-3791. doi:10.1175/JCLI3824.1.

Samuelsson, P., C.G. Jones, U. Willen, A. Ullerstig, S. Gollvik, U. Hansson, C. Jansson, E. Kjellstrom, et al. 2011. The Rossby centre regional climate model RCA3: Model description and performance. Tellus Series A-Dynamic Meteorology and Oceanography 63: 4-23. doi:10.1111/j.1600-0870.2010.00478.x.

Satilmis, H.H., A.D. Gordina, L. Bat, R. Bircan, M. Culha, M. Akbulut, and A.E. Kideys. 2003. Seasonal distribution of fish eggs and larvae off sinop (the southern Black Sea) in 1999-2000. Acta Oecologica 24: S275-S280.

Smith, S., T. Wigley, N. Nakicenovic, and S. Raper. 2000. Climate implications of greenhouse gas emissions scenarios. Technological Forecasting and Social Change 65: 195-204. doi: 10.1016/S0040-1625(99)00099-2.

Stock, C.A., M.A. Alexander, N.A. Bond, K.M. Brander, W.W.L. Cheung, E.N. Curchitser, T.L. Delworth, J.P. Dunne, et al. 2011. On the use of IPCC-class models to assess the impact of climate on Living Marine Resources RID A-2413-2008. Progress in Oceanography 88: 1-27. doi:10.1016/j.pocean.2010.09.001.

Tomczak, M.T., S. Niiranen, O. Hjerne, and T. Blenckner. 2012. Ecosystem flow dynamics in the Baltic Proper-using a multitrophic dataset as a basis for foodweb modelling. Ecological Modelling 230: 123-147. doi:10.1016/j.ecolmodel.2011.12.014.

Uppala, S., P. Kallberg, A. Simmons, U. Andrae, V. Bechtold, M. Fiorino, J. Gibson, J. Haseler, et al. 2005. The ERA-40 reanalysis RID B-5782-2008 RID B-7184-2008. Quarterly Journal of the Royal Meteorological Society 131: 2961-3012. doi: 10.1256/qj.04.176.

\section{AUTHOR BIOGRAPHIES}

Brian R. MacKenzie $(\varangle)$ is a professor of marine fish population ecology at the Center for Macroecology, Evolution and Climate, National Institute for Aquatic Resources (DTU-Aqua), Technical University of Denmark. His current research interests are impacts of climate change and human impacts on marine fish populations and dynamics in the Baltic Sea and North Atlantic Ocean.

Address: Center for Macroecology, Evolution and Climate, National Institute for Aquatic Resources, Technical University of Denmark (DTU Aqua), Charlottenlund Castle, 2920 Charlottenlund, Denmark. e-mail: brm@aqua.dtu.dk

H. E. Markus Meier is an adjunct professor at Stockholm University and head of the Oceanographic Research Unit at the Swedish Meteorological and Hydrological Institute (SMHI). His current research interests focus on the analysis of climate variability and the impact of 
climate change on the physics and biogeochemical cycles in the Baltic Sea, North Sea and Arctic Ocean.

Address: Swedish Meteorological and Hydrological Institute, 60176 Norrköping, Sweden.

e-mail: markus.meier@smhi.se

Martin Lindegren is a research scientist at Scripps Institute of Oceanography. His research interests include modeling of long-term dynamics of fish populations and food webs.

Address: National Institute for Aquatic Resources, Technical University of Denmark (DTU Aqua), Charlottenlund Castle, 2920 Charlottenlund, Denmark.

e-mail: mli@aqua.dtu.dk

Stefan Neuenfeldt is a research scientist at the National Institute for Aquatic Resources (DTU-Aqua), Technical University of Denmark. His research interests are species interactions among fish, fish migration, and habitat utilisation.

Address: National Institute for Aquatic Resources, Technical University of Denmark (DTU Aqua), Charlottenlund Castle, 2920 Charlottenlund, Denmark.

e-mail:stn@aqua.dtu.dk

Margit Eero is a research scientist at the National Institute for Aquatic Resources (DTU-Aqua), Technical University of Denmark. Her research interests are long-term dynamics of fish populations, ecological indicators, and human impacts on populations and food webs.
Address: National Institute for Aquatic Resources, Technical University of Denmark (DTU Aqua), Charlottenlund Castle, 2920 Charlottenlund, Denmark.

e-mail: mee@aqua.dtu.dk

Thorsten Blenckner is a senior scientist at the Baltic Nest Institute and the Department of Systems Ecology of the Stockholm University. His research interests include food-web dynamics, multiple stressor effects on ecosystems, and climate change research.

Address: Baltic Nest Institute, Stockholm Resilience Centre, Stockholm University, 10691 Stockholm, Sweden.

e-mail: thorsten.blenckner@stockholmresilience.su.se

Maciej T. Tomczak PhD is a researcher at Baltic Nest Institute, Stockholm University. His research concentrates on food-web and fisheries interactions, integrated ecosystems assessment and management of marine ecosystems.

Address: Baltic Nest Institute, Stockholm Resilience Centre, Stockholm University, 10691 Stockholm, Sweden.

e-mail: maciej.tomczak@stockholmresilience.su.se

Susa Niiranen is a PhD candidate at the Baltic Nest Institute and the Department of Systems Ecology of the Stockholm University. Her research is mainly focused on the Baltic Sea food-web dynamics and their response to environmental change.

Address: Baltic Nest Institute, Stockholm Resilience Centre, Stockholm University, 10691 Stockholm, Sweden.

e-mail: susa.niiranen@stockholmresilience.su.se 